\title{
Review
}

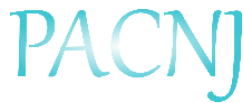

\section{Effects of Abdominal Massage to Overcome Gastrointestinal Dysfunction in Patients in Intensive Care Unit: a literature review}

Cecep Eli Kosasih ${ }^{1}$ Alisha Dewi Andriani ${ }^{2}$, Astriani Ayu Lestari ${ }^{2}$, Friska Maulia Sekarjati ${ }^{2}$, Hanifa Iqomatulhaq ${ }^{2}$, Janet Jessica Audini², Mia Vauziah Lestary², Mohamad Ramdan², Renie Nurcholivatun ${ }^{2}$, Risna Risela Agustin ${ }^{2}$, Tanti Almuwaroh ${ }^{2}$, Yoga Abdul Manaf ${ }^{2}$

${ }^{1}$ Lecturer, Faculty of Nursing, Universitas Padjadjaran

${ }^{2}$ Student, Faculty of Nursing, Universitas Padjadjaran

\section{ARTICLE INFO}

Article history:

Received 29-11-2019

Received in revised

from 05-12-2019

Accepted 05-12-2019

\section{Keyword:}

Abdominal massage,

Gastrointestinal

function,

Intensive Care Unit.

\section{Other Information:}

Email of Author cecep.e.kosasih@

unpad.ac.id

Corresponding

Author Cecep E

Kosasih

And other -

\begin{abstract}
Patients who are receiving treatment at the ICU have at least one symptom of gastrointestinal dysfunction including decreased bowel noise, abdominal distension, constipation, decreased frequency of defecation, and increased GRV (gastric residual volume). Nonpharmacological interventions that can be done to improve gastrointestinal function include abdominal massage. This paper aimed to conduct a literature review on the effects of abdominal massage to overcome gastrointestinal dysfunction in patients in the ICU. Articles taken from the Google Scholar and Science Direct electronic databases with the keywords abdominal massage, gastrointestinal function, bowel function, and ICU were published from 2015 to 2019. There were four research articles discussing abdominal massage to improve gastrointestinal function. Three articles used the Randomized Controlled Design method and one article used the Quasi Experimental method. Abdominal massage has a positive effect to improve gastrointestinal function in patients receiving treatment in the ICU. Improved gastrointestinal function that can be seen from the existence of a faster time in the reduction in gastric residual volume (GRV), decreased abdominal circumference, decreased gastric distension, and decreased the incidence of constipation. It is expected that abdominal massage can be applied by ICU nurses considering this intervention has the effectiveness in terms of time and funding.
\end{abstract}





\section{Introduction}

Intensive care unit (ICU) is a care unit for patients with chronic, life-threatening illnesses that require continuous care, monitoring, and use of support equipment and medications to save lives. Characteristics of patients treated in the ICU include decreased consciousness, experiencing one or more organ failure, weakness, oversedation, and invasive medical devices installed such as ventilators and require inotropic drugs, anti-arrhythmic drugs that require continuous titration.

Studies showed that as many as $60 \%$ of ICU patients have at least one symptom of gastrointestinal dysfunction during a treatment period such as bleeding, decreased bowel noise (decreased mortality), and abdominal distension. In addition to the gastrointestinal system appeared several other problems such as constipation, decreased frequency of defecation, and increased GRV (Gastric Residual Volume). Constipation or increase in GRV can occur due to the use of mechanical ventilation and the use of PEEP. The use of mechanical ventilation with PEEP can result in increased intrathoracic pressure. Increased intrathoracic pressure results in a decrease in venus return which causes a decrease in cardiac output, this condition causes the body to compensate by reducing blood flow to the gastrointestinal system or so-called splanchnic hypoperfusion. This hypoperfusion results in gastrointestinal mucosal ischemia, decreased bicarbonate secretion, and decreased gastrointestinal motility (Ego, Preiser, \& Vincent, 2015; Mostafa, Bhandari, Ritchie, Gratton, \& Wenstone, 2003). In addition, ICU patients with long bed rest tend to get a fiber diet that was less than necessary. In a study stated that the increase in GRV occurred mostly in the administration of enteral nutrition through gravity drip compared with intermittent feeding because gradually enteral nutrition would maximize gastric emptying (Munawaroh, Handoyo, \& Diah, 2012).

Several studies have shown that $72 \%$ of patients in the ICU room experience constipation due to mechanical ventilation after 72 hours (de Souza Guerra, Mendonça, \& Marshall, 2013). Then as much as $64.1 \%$ was due to total bed rest, as much as $40.5 \%$ was due to various types of nutritional therapy, and $45.8 \%$ was due to the use of opioid therapy (Sharma, Kaur, \& Garg, 2007).

Critical patients who use mechanical ventilators are at risk of increasing GRV and prone to vomiting so that it can cause aspiration of gastric contents which is a risk factor for developing pneumonia due to ventilator (VAP) as well as gastroaesofagal reflux. In addition, patients who use mechanical ventilators must be prevented and treated in case of constipation because it can result in increased use of mechanical ventilation and longer patient care days. Based on a study showed as many as $42 \%$ of patients who experience constipation will experience failure due to mechanical ventilation, because constipation can cause abdominal distension, discomfort, and anxiety (Mostafa et al., 2003). Abdominal distension itself can inhibit the development of diaphragms, reduce lung compliance, and improve respiratory work thereby prolonging the process of weaning mechanical ventilation (de Azevedo \& Machado, 2013).

Non-pharmacological interventions that can be performed on patients in the ICU who experience gastrointestinal dysfunction can be done abdominal massage. Where abdominal massage is useful to prevent and reduce interference with the gastrointestinal system. The mechanism of action of abdominal massage was to reduce contractions and tension in the abdominal muscles, increase motility and increase secretion in the gastrointestinal system and increase the effect on sphincter relaxation, so that the mechanism of gastrointestinal action was easier and facilitate the discharge of stool (Kahraman \& Ozdemir, 2015). ICU nurses have an important role in facilitating the basic needs of patients related to gastrointestinal function, namely providing nutrition, facilitating elimination and preventing complications of gastrointestinal system failure in critical patients treated in the ICU (Bond \& Hallmark, 2018). The neglect of ICU nurses in monitoring gastrointestinal function can increase the number of human error due to failure to rescue (FTR), so that the mortality and morbidity of ICU patients increased (Bond \& Hallmark, 2018). Regarding to the importance of the management of gastrointestinal function in patients treated in the ICU, so researchers interested in conducting a literature review on the effects of abdominal massage to overcome gastrointestinal dysfunction in patients treated in the Intensive Care Unit.

\section{Method}

\section{Types of research}

Articles that qualify in this literature review were the Randomized Controlled Design method, Randomized Clinical Trial, Quasi Experimental with 
full text publication texts in the last 5 years (2015 - Data collection schema

2019).

\section{Participant Type}

Adult patients treated in the Intensive Care Unit.

\section{Types of Interventions and Languages}

The interventions applied in this study were abdominal massage. The research that was taken can use English or Indonesian in the public script.

\section{Type of Result}

Types of outcome measures focus on studies that have the results of the effectiveness of abdominal massage on gastrointestinal function.

\section{Research Methods}

Article searching strategies were carried out using computers through electronic databases such as Science Direct and Google Scholar with the keywords "abdominal massage", "gastrointestinal function", "bowel function", "ICU", "RCT". The search focused on articles published in 2014 - 2019 with the criteria: (1) is the result of direct research (original research), both experimental and quasi-experiments; (2) all participants consisted of patients treated in the Intensive Care Unit, and; (3) the article deals with the application of abdominal massage to gastrointestinal function.

\section{Review method}

Search for articles was done through a predetermined electronic database. After the article was found, then an analysis was carried out in the journal and abstract to determine the suitability of the article with the specified criteria. Manuscripts or full texts of the corresponding articles were further analyzed further and thoroughly. 


\section{Results}

Various types of interventions that can be given to determine the effects of abdominal massage are included in the 4 studies discussed in this paper. The results of his study were summarized in Table 1.

Table 1 . The results of each study

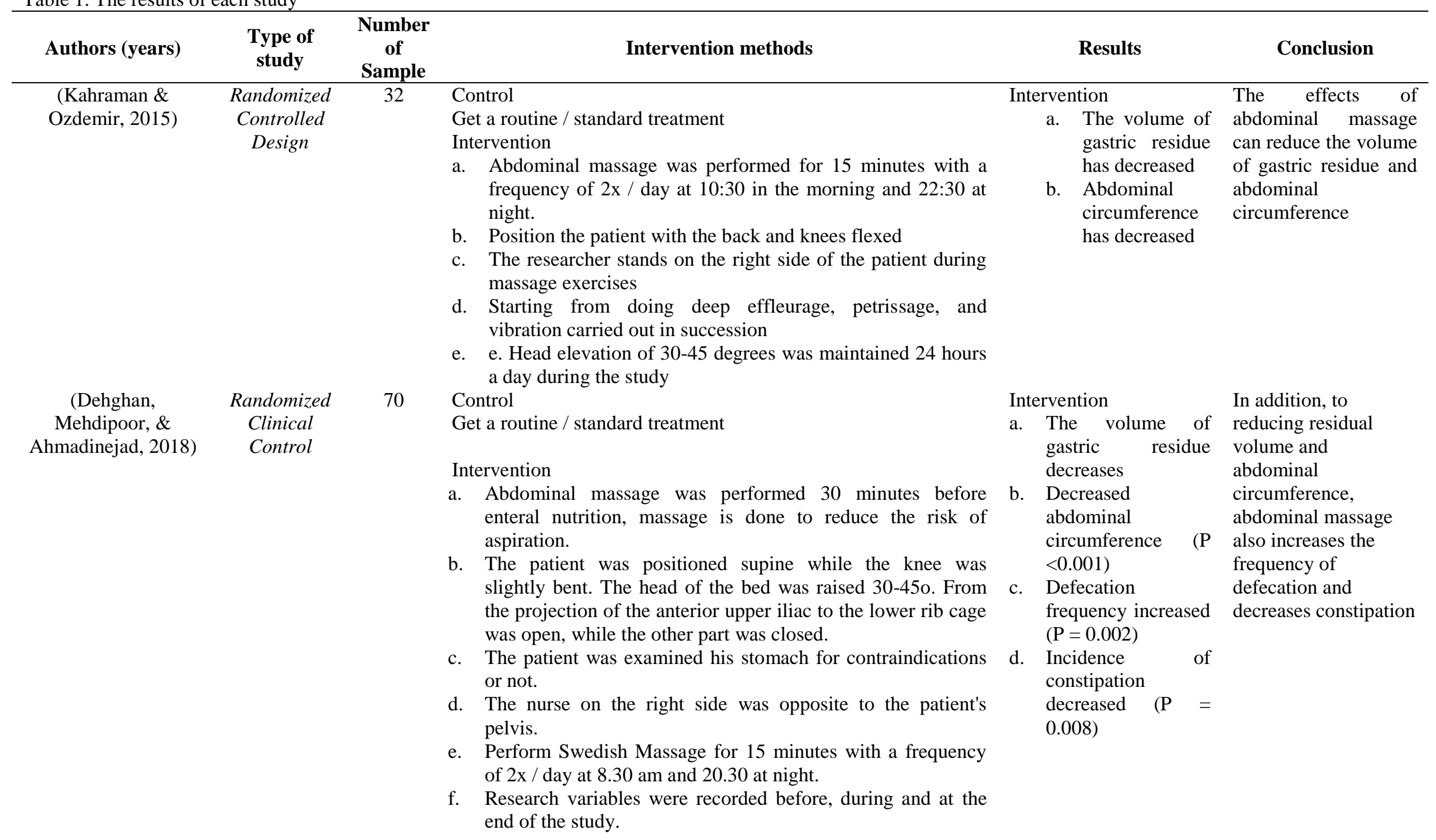


ISSN 2715 - 6060

Padjadjaran Acute Care Nursing Journal Vol 1 No 1 Desember 2019

(Momenfar, Abdi, Salari, Soroush, \&

Hemmatpour, 2018)

Randomized
Clinical
Trial

\author{
Control \\ Get a routine / standard treatment
}

Intervention

a. Get 3 days treatment

b. Get abdominal massage 2 times a day

c. The distance between massage was 2 hours

d. Every day an intervention was performed and 1 hour after the second massage, gastric residual volume was measured and examined

e. There are 5 techniques performed in abdominal massage

- Techniques to wipe the skin of the abdomen (stomach)

- Performed by placing the dominant hand above the abdomen (abdomen) and the other hand above it then do the emphasis.

○ The skin of the abdomen (stomach) was squeezed using fingers like kneading dough.

- Give movement (wobble) along the armpit from top to bottom and vice versa.

- Place the fingers in the intercostal space, pulling the abdominal skin with the appropriate pressure. Data lubricating gel was carried out to facilitate the massage process. During the massage process, the patient was in a lying position with the angle between the bed and the patient's head $30-45^{\circ}$, and the patient's legs were placed on a pillow

(Estri, Fatimah, \& Prawesti, 2016)

Quasi

Experimental

post test only

non

equivalent

control

group
Intervention

a. The residual

volume of the

stomach showed a

mean result of

$97.30 \mathrm{cc}$ while the

control was

$143.46 \mathrm{cc}$ ( $\mathrm{p}$ value

$<0.05$ )

b. The volume of

gastric residue from day to day showed

smaller

Swedish massage

intervention

a. Occurrence of

constipation $45.4 \%$

Effeurage intervention

a. Constipation

incidence $27.2 \%$
The volume of

residuals is getting smaller day by day

Effleurage techniques increase comfort and are more efficient with less time and energy 


\section{Discussion}

This literature review focused on the discussion of the effects of abdominal massage to overcome gastrointestinal dysfunction in patients in the Intensive Care Unit (ICU). From the four research articles analyzed, the results showed that abdominal massage could improve gastrointestinal function, including reducing gastric residual volume (GRV), reducing abdominal distension, reducing the risk of constipation, and facilitating patient comfort.

From the analysis results in articles 1,2 and 3 it was found that the intervention of abdominal massage could significantly reduce GRV. In line with the study of Uysal, Eser and Akpinar (2012) who conducted research related to the effects of abdominal massage to purify GRV in patients receiving intermittent enteral therapy, it was explained that massages performed on the abdominal area through abdominal massage can increase peristalsis, reduce pressure or internal tension abdomen and reduce food transit time in the gastrointestinal tract (Uysal, Eser, \& Akpinar, 2012). This was also supported by a study found that abdominal massage can stimulate parasympathetic nerves thereby increasing the activity of the gastrointestinal system in digesting food and accelerating gastric emptying time (Lämås, Graneheim, \& Jacobsson, 2012).

Faster GRV emptying time as an effect of abdominal massage intervention can provide several benefits for the gastrointestinal system itself and also other body systems. A faster decrease in GRV allowed patients to get faster enteral nutrition. Early nutrition (early enteral feeding) can help maintain gastrointestinal structure and function, optimize the immune system, optimize wound healing and prevent the breakdown of excessive body fat (Dehghan et al., 2018). In addition, patients who got early enteral feeding can avoid the risk of malnutrition, reduce discomfort due to nausea, vomiting and abdominal distension.

A faster decline or emptying of GRV also has positive implications for decreasing the incidence of ventilator accuired pneumonia (VAP). This was explained in research article 2 conducted by Kahraman and Odzemir (2015). In this study, the results showed that after an abdominal massage intervention in ICU patients who installed ventilators, there was a decrease in the VAP ratio in the intervention group with a percentage of $6.3 \%$ and the ratio in the control group by $31.3 \%$, but the difference in the intervention and control groups did not experience significant difference ( $p>0.05$ ). The decrease in the ratio was still associated with a decrease in GRV, which was a relatively long time to discharge the GRV which can increase the risk of aspiration or reflux of gastric fluid into the lungs and cause VAP (Kahraman \& Ozdemir, 2015). In the study also confirmed that high GRV can increase the risk of VAP 5 times higher compared to patients with faster GRV evacuation time (Kahraman \& Ozdemir, 2015).

\section{Conclusions}

The results of this literature review showed that the intervention of abdominal massage has a positive effect to improve gastrointestinal function in patients receiving care in the ICU. An improved gastrointestinal function that has improved can be seen from the existence of a faster time in the reduction in gastric residual volume (GRV), decreased abdominal circumference, decreased gastric distension, and decreased the incidence of constipation. The mechanism of movement carried out in abdominal massage allowed increased blood circulation to the gastrointestinal system, accelerating the transit time of food in the gastrointestinal tract and increasing the perislatic movement of the gastrointestinal system so that gastrointestinal function can be improved. Nurses in the ICU room are expected to consider implementing abdominal massage interventions, reviewing that these interventions can help prevent gastrointestinal complications or dysfunction and are relatively safe interventions with time-effectiveness and cost effectiveness. 


\section{Implication}

ICU nurses have an important role in providing care to patients in the ICU. Among the tasks that ICU nurses must do was make decisions and keep patients safe and avoid complications from occurring, including complications that can occur in the gastrointestinal system (Bond \& Hallmark, 2018). The role of ICU nurses that can be done to prevent complications and improve gastrointestinal function in general was to help provide nutrition at the right time by determining early enteral feeding, checking whether the patient has intolerance to the gastrointestinal system, facilitating patients to get the right type of nutrition, checking the placement of the end of the hose NGT, determine the number of calories the patient needs, and check whether the patient's GRV is still large or not (Momenfar et al., 2018).

One type of non-pharmacological intervention that can be done by ICU nurses to prevent complications and improve gastrointestinal function is by performing abdominal massage interventions. Abdominal massage was an intervention that was relatively safe and minimizes side effects, efficient in terms of funding, and efficient from the time of the action, which was about 7-15 minutes (Kahraman \& Ozdemir, 2015; Uysal et al., 2012). As discussed above, abdominal massage can reduce GRV, reduce gastric distension, reduce constipation status and facilitate patient comfort, which indicates an increase in gastrointestinal function and reduce the incidence of gastrointestinal complications in patients. In this regard, it is expected that by implementing abdominal massage interventions, ICU nurses can also help prevent complications of gastrointestinal dysfunction so that the incidence of failure in saving patient complications or Failure to Rescue of the gastrointestinal system can be minimized to accelerate recovery of the patient's condition and shorten the patient's length of stay in the ICU room ((Bond \& Hallmark, 2018).

\section{References}

Bond, L., \& Hallmark, B. (2018). Educating Nurses in the Intensive Care Unit About Gastrointestinal Complications: Using an Algorithm Embedded into Simulation. Critical Care Nursing Clinics, 30(1), 7585.

de Azevedo, R. P., \& Machado, F. R. (2013). Constipation in critically ill patients: much more than we imagine. Revista Brasileira de terapia intensiva, 25(2), 73.

de Souza Guerra, T. L., Mendonça, S. S., \& Marshall, N. G. (2013). Incidence of constipation in an intensive care unit. Revista Brasileira de terapia intensiva, $25(2), 82$.

Dehghan, M., Mehdipoor, R., \& Ahmadinejad, M. (2018). Does abdominal massage improve gastrointestinal functions of intensive care patients with an endotracheal tube?: a randomized clinical trial. Complementary therapies in clinical practice, 30, 122-128.

Ego, A., Preiser, J.-C., \& Vincent, J.-L. (2015). Impact of diagnostic criteria on the incidence of ventilatorassociated pneumonia. Chest, 147(2), 347-355.

Estri, A. K., Fatimah, S., \& Prawesti, A. (2016). Perbandingan Abdominal Massage dengan Teknik Swedish Massage dan Teknik Effleurage terhadap Kejadian Konstipasi pada Pasien yang Terpasang Ventilasi Mekanik di ICU. Jurnal Keperawatan Padjadjaran, 4(3).

Kahraman, B. B., \& Ozdemir, L. (2015). The impact of abdominal massage administered to intubated and enterally fed patients on the development of ventilator-associated pneumonia: a randomized controlled study. Int J Nurs Stud, 52(2), 519-524.

Lämås, K., Graneheim, U. H., \& Jacobsson, C. (2012). Experiences of abdominal massage for constipation. $J$ Clin Nurs, 21(5-6), 757-765.

Momenfar, F., Abdi, A., Salari, N., Soroush, A., \& Hemmatpour, B. (2018). Studying the effect of abdominal massage on the gastric residual volume in patients hospitalized in intensive care units. Journal of intensive care, 6(1), 47.

Mostafa, S., Bhandari, S., Ritchie, G., Gratton, N., \& Wenstone, R. (2003). Constipation and its implications in the critically ill patient. British journal of anaesthesia, 91(6), 815-819.

Munawaroh, S. W., Handoyo, \& Diah, A. (2012). Efektifitas Pemberian Nutrisi Enteral Metode Intermittent Feeding Dan Gravity Drip Terhadap 
Volume Residu Lambung Pada Pasien Kritis Di Ruang ICU RSUD Kebumen

Sharma, S. K., Kaur, K., \& Garg, R. (2007). Factors affecting bowel movement in critically ill patients. Nursing and Midwifery Research, 3(2).

Uysal, N., Eser, I., \& Akpinar, H. (2012). The effect of abdominal massage on gastric residual volume: a randomized controlled trial. Gastroenterology Nursing, 35(2), 117-123. 